\title{
At home: Field education during lockdown
}

${ }^{1}$ University of Otago, Social and Community Work, New Zealand

${ }^{2}$ The Salvation Army, New Zealand
AOTEAROA

NEW ZEALAND SOCIAL WORK 33(2), 114-117.

CORRESPONDENCE TO: Liz McCafferty

liz.mccafferty@otago.ac.nz

\author{
Yesse Cox ${ }^{1}$, David McKenzie ${ }^{2}$, Bronwyn Powell-Grub ${ }^{2}$ and Liz McCafferty ${ }^{1}$
}

\begin{abstract}
Field education during the 2020 Aotearoa New Zealand Covid-19 lockdown was a new experience for social work educators and students alike. This case study captures the experience of one social work student during this time while on placement at the Salvation Army. Included in the account are the perspectives of the Community Ministries Manager, the placement supervisor and the placement field coordinator. Due to the Covid-19 restrictions, the student undertook the placement while at home. A pandemic can offer students opportunities to learn about managing difficult situations. Reflection on the experience provided insight into what helped and what could have been done differently. Regular debriefing, supervision and a postcrisis debrief were all important elements that aided the learning and supported the wellbeing of the student.
\end{abstract}

KEYWORDS: Field education; Covid-19; Social work education; Student experience

In March 2020, Aotearoa New Zealand went into lockdown, intending to eliminate Covid-19 from the country. At that time Yesse, a social work student at the University of Otago was one month into her final placement at the Salvation Army. The following account is Yesse's impression of field education while under lockdown conditions. It includes the perspective of those working alongside Yesse to support her placement: David McKenzie, Manager, the Salvation Army Dunedin; Bronwyn Powell-Grub, Yesse's supervisor; and Liz McCafferty, Field Co-ordinator, University of Otago. There were several organisational supports required to make the placement work both from a practical perspective and to meet policy requirements. This brief Viewpoint article explores some of the lessons learned from the experience.

\section{Yesse's account}

In March 2020, I was one month into my placement at the Salvation Army working alongside transitional housing social workers and spending one day a week in the foodbank. The placement was going well and the focus was on observing social workers and formulating learning goals. There were many discussions at the Salvation Army about Covid-19, but as my thoughts were taken up with working towards developing a caseload of my own, I was not following the news closely. The news about COVID-19 did not make me think there would be major changes to my placement. The Salvation Army was an essential service and the manager (David) had spoken me about being involved in a work bubble. I was comfortable with this plan, as it seemed that my placement routine would not be disrupted. In conversations with David, we discussed how the Salvation Army would continue to work during the pandemic under government guidelines.

At the time lockdown was announced, I was in town doing the groceries, oblivious to the news. My university field education coordinator ( $\mathrm{Liz}$ ) rang me to say that the country would be going into lockdown in two days. Liz sounded optimistic about the placement continuing with no issue. Two 
days later I got another call from Liz, she told me that the University of Otago had decided that I could not attend placement onsite. I was pulled off placement, which was quite a shock as both David and Liz had seemed open to my continuing. I had assumed that there would be no problem continuing with placement, as it was in an organisation providing an essential service.

The following week Liz got in touch to say that placement could continue at home. David sent me the tasks that would shape my new lockdown-based placement.

The outline was very different from my placement up to that point, so I needed to read the description and think before agreeing to continue. The new description of tasks included operating the phone lines into the service while I was at home and responding to any situations this presented. It was expected that most calls would be referrals for the foodbank and I was concerned that this might not meet my final assessment requirements. It was difficult to envision how my placement would be on a day-to-day basis by just reading the job description. While Liz indicated that I had a choice whether to accept the new placement, my financial constraints meant I had no other option than to continue. Passing the placement was important, but so, too, was the consideration of adding to debt if I decided to delay.

Returning to placement, it was clear that everyone had a great deal of work to do and the pressure was on. Observing this validated my decision to stay, as my contribution to the work had the potential to take the pressure off the other staff. The workload at the Salvation Army had risen due to a sharp increase in foodbank referrals. Compounding this was the fact that the foodbank usually had many volunteers supporting the work, so the restriction on volunteering under the level 4 rules increased the work for paid staff. Several workers had not worked in the foodbank before and had to learn this skill on the job. The foodbank was normally open a set number of days a week, but during level 4 the foodbank operated five days a week.

My role during lockdown involved being part of a team of people taking all the calls coming into the local branch of the Salvation Army. This kind of work was new to me and I wanted to be able to do a good job. I was nervous initially that I would give the wrong advice to people calling in. What really helped was David's availability. David let me know that I was able to contact him any time during a shift and that he would call me at the end of each shift. Initially, I phoned him a lot because I did not know how to respond to some of the phone calls and he was very helpful. It was reassuring to be able to debrief with someone, as David made himself available whenever I needed to talk. I was not alone in my uncertainty, as all the staff within the team were trying to work out how to do their jobs at level 4 . Team meetings were held each morning via video conference and I talked individually with other members of the team. They wanted to hear how I was going and I wanted to hear how they were going.

I was more stressed by the work than I let on at the time. There were so many calls coming in in the first couple of weeks. In those weeks there would be two or three calls waiting while I was on the phone to someone else. It was non-stop and many people calling were in distress. Many people were suffering financially and needed food parcels. Some were facing household financial deprivation for the first time. Others just wanted to ring and talk, as they were living on their own and felt isolated and alone. Because I wanted the placement to go well, I did not talk about how hard it was on me emotionally. Support was on offer from weekly supervision; however, at the time of the events I was focused on getting through the day to day. The usual coping strategies that I relied on such as going to the gym or meeting up with friends were not available to me. 
Conversations with staff who were doing the same work and also working remotely helped me manage the stress and made me feel less isolated.

I learned so much doing my placement in the way I did. I learned to be adaptable and to be able to do the work alongside the team. A learning opportunity came from receiving all the calls from around the community. I got to know how the community and individual members of it were being affected by lockdown. I had calls from Civil Defence referring people and calls from individuals who needed help. It gave me a good idea of how the community was coping and who was struggling-it was a completely different one than I had expected, as the lockdown affected many people who had not previously been struggling financially.

A positive aspect that came out of working in a crisis was that I formed strong relationships with the team I was working with. The shared experience of working during lockdown created a bond. When the lockdown was over and I was back on site it was easier to work collaboratively because of the relationships formed during lockdown. Working alongside the team as closely as I did gave me insight into how much the staff cared about the work they were doing. They genuinely cared about each person they worked with and the long-term outcomes for that person. This was demonstrated in small, significant, caring actions and the language they used when speaking about clients. The staff would listen to people, allow them to share their story and would do whatever they could to support community need. It demonstrated to me that you can treat people as human beings while working within complex systems.

\section{The backdrop}

Individuals from the Salvation Army and the University of Otago communicated to decide what needed to be put in place to provide Yesse with optimal levels of support. Bronwyn (supervisor) and David (manager) decided that they were committed to providing extra levels of contact to ensure that Yesse was well supported. This initially involved daily phone calls from the manager who became Yesse's field educator. The whole team had daily team meetings in the morning via video conference, in which Yesse was included. The field education coordinator committed to texting, emailing, and calling as regularly as was required by Yesse. Bronwyn provided supervision over the phone, on top of the extra work she had as a result of the pandemic. Bronwyn and David were committed to supporting Yesse's placement through to completion. They had a strong sense of loyalty to Yesse to ensure that her education could continue despite the lockdown.

\section{Lessons learned}

Elements of this placement provide useful considerations for field education placements in crisis situations. In a placement of this nature, the learning needs of the students have to be weighed up against the organisation's capacity to include a student during a crisis. The health of the community is the primary consideration. Without the manager's willingness to be a field educator and the supervisor to continue to offer supervision, the placement would not have been able to continue. As the pandemic environment becomes our established way of working, social work students' learning needs will continue to be important, alongside consideration of the capacity of the organisation to support the placement.

Communication through technology was a significant factor in the success of placement. The support requirements for a placement undertaken at home involved using technology in innovative ways. Video conferencing, texting, and phone calls all facilitated continued communication and Yesse was supported to do the work. Overcoming the challenge of supporting the student without face-to-face contact was 
necessary to make this placement possible. In this way, even though the student is physically isolated, they can remain connected.

A student in this situation might not hold all the same information surrounding the crisis as the rest of the people involved. While experienced social workers might be used to dealing with the competing demands of the practice environment along with demands outside of work, students are not always practised at this (Prost et al., 2016). Students have that extra level of concern around finances and passing the placement, which may mean their focus is quite different from other parties involved. Field education coordinators need to have full and frank conversations with students about the implications of a crisis. Being transparent with information in this way reduces confusion.

The effects of the crisis may mean those involved cannot fully reflect during the events, as they are focused on the immediate decision making (Prost et al., 2016). Students who are in the midst of a crisis situation will respond in human ways, focusing on the task in front of them and getting through it as best they can. Reactions of the brain to the stress can have the positive effect of helping them to accomplish tasks, but it can also restrict their ability to reflect with depth on what is happening (Prost et al., 2016). Educating students in the initial phases of a crisis placement about the human stress response has the benefit of lessening the impact of this stress (Prost et al., 2016). From Yesse's experience, regular daily debriefs were what reduced her stress levels and helped her progress with the work. What was missing from the structure of this placement was an externally facilitated debrief after the placement was over. We know from practice that this is beneficial for crisis practitioners and students. (Findley et al., 2017). This would have been useful for the student, manager, supervisor, and field coordinator.
With the right support, placements undertaken at home in a crisis can provide great learning opportunities. The experience of managing a challenging situation successfully can boost confidence in the student's abilities. This demonstration of resilience offers the student a sense of their strength when situations are challenging (Papouli et al., 2020). We know that positive relationships with others in the organisation facilitates learning (Young et al., 2016). Going through a crisis situation together can strengthen bonds and provide a good learning environment.

\section{Conclusion}

The factors required to make a field education experience possible in national emergency conditions will not exist for every organisation or every student. Students need to be in a position where they are prepared to undertake a different placement from what may have been originally outlined to them. If we want to continue to have more social workers coming into the workforce, finding ways to provide social work experience amongst pandemic conditions is necessary. As the pandemic continues and we adapt to a different way of learning, we must also adapt our placement approach to support social work education.

\section{References}

Findley, P. A., Pottick, K. J., \& Giordano, S. (2017). Educating graduate social work students in disaster response: A real-time case study. Clinical Social Work Journal, 45(2), 159-167.

Papouli, E., Chatzifotiou, S., \& Tsairidis, C. (2020). The use of digital technology at home during the COVID-19 outbreak: Views of social work students in Greece. Social Work Education, 39(8), 1107-1115. doi:10.1080/0 2615479.2020.1807496

Prost, S., Lemieux, C., \&. Ai, A. (2016). Social work students in the aftermath of Hurricanes Katrina and Rita: Correlates of post-disaster substance use as a negative coping mechanism. Social Work Education, 35(7), 825-844. doi:10.1080/02615479.2016.1187720

Young, J. E., Williamson, M. I., \& Egan, T. G. (2016). Students' reflections on the relationships between safe learning environments, learning challenge and positive experiences of learning in a simulated GP clinic. Advances in Health Sciences Education, 21(1), 63-77. 